\title{
Interleukin-1 $\beta+3954$ polymorphisms and risk of external apical root resorption in orthodontic treatment: A meta-analysis
}

\author{
F.-L. Wu' ${ }^{1}$ L.-Y. Wang ${ }^{2}$, Y.-Q Huang ${ }^{3}$, W.-B. Guo ${ }^{4 *}$, C.-D. Liu ${ }^{4 *}$ and S.-G. Li ${ }^{2 *}$ \\ ${ }^{1}$ Department of Stomatology, Second People's Hospital of Foshan, \\ Guangdong Medical College, Zhanjiang, Guangdong, China \\ ${ }^{2}$ Department of Stomatology, \\ Affiliated Foshan Hospital of Southern Medical University, Guangzhou, \\ Guangdong, China \\ ${ }^{3}$ Department of Hepatobiliary Surgery, \\ Nanfang Hospital of Southern Medical University, Guangzhou, Guangdong, China \\ ${ }^{4}$ Department of Urology, The Affiliated Hospital of Southern Medical University, \\ Guangzhou, Guangdong, China \\ *These authors contributed equally to this study. \\ Corresponding authors: S.-G. Li / C.-D. Liu \\ E-mail: lsglishuguang@163.com / lcdliucundong@163.com
}

Genet. Mol. Res. 12 (4): 4678-4686 (2013)

Received November 15, 2012

Accepted July 30, 2013

Published October 18, 2013

DOI http://dx.doi.org/10.4238/2013.October.18.6

\begin{abstract}
The purpose of this meta-analysis was to determine whether genetic variants of the interleukin-1 $\beta[+3954 \mathrm{C}>\mathrm{T}(\mathrm{rs} 1143634)]$ $(\mathrm{IL}-1 \beta+3954 \mathrm{C}>\mathrm{T})$ gene polymorphisms were associated with orthodontic external apical root resorption (EARR). A meta-analysis was carried out using data entered into the PubMed and Embase electronic databases before October 5, 2012. A total of 7 studies were identified for meta-analysis. The strength of the relationship between IL-1 $\beta+3954 \mathrm{C}>\mathrm{T}$ polymorphism and the risk of EARR was assessed using odds ratio (OR). The studies provided overall OR estimates for EARR. Overall, the variant genotypes (CC and CT) of the IL-1 $\beta+3954$ $\mathrm{C}>\mathrm{T}$ polymorphism were unassociated with EARR risk compared with
\end{abstract}


the TT homozygote [CC vs TT, OR $=1.28,95 \%$ confidence interval $(95 \% \mathrm{CI})=0.27-6.08 ; \mathrm{CT}$ vs $\mathrm{TT}, \mathrm{OR}=0.74,95 \% \mathrm{CI}=0.11-5.02]$. Similarly, no associations were found in the dominant and recessive models (dominant model, $\mathrm{OR}=1.08,95 \% \mathrm{CI}=0.24-4.86$; recessive model, $\mathrm{OR}=1.85,95 \% \mathrm{CI}=0.87-3.93)$. No publication bias was found, and no association was apparent between the IL- $1 \beta+3954 \mathrm{C}>\mathrm{T}$ polymorphism and risk of EARR in orthodontic treatment patients. Further multicenter and better-controlled studies are required to confirm these findings.

Key words: External apical root resorption; Interleukin-1 $\beta$; Orthodontic; Polymorphism; Meta-analysis

\section{INTRODUCTION}

External apical root resorption (EARR) is an undesirable sequela of orthodontic treatment in some patients that results in the permanent loss of tooth structure from the root apex. The incidence of minor physiological root resorption is $86.4 \%$ in patients between the ages of 16 and 32 years and $96.4 \%$ in patients aged 32-50 years (Wehrbein et al., 1995). A few extreme resorption phenomena have been documented that might have had detrimental consequences for the patients. No direct evidence existed for a genetic predisposition until a 1997 report by Harris et al. (1997), who explored the hypothesis of genetic influence on EARR using a sibling-pair model. From then on, genetic predisposition for root resorption has been the subject of numerous investigations (Harris et al., 1997, Al-Qawasmi et al., 2003a,b, 2006).

The first description of a genetic marker that identifies subjects who are more likely to have EARR was established by Al-Qawasmi et al. (2003a), who identified an association between EARR during orthodontic treatment and the interleukin-1 $[+3954 \mathrm{C}>\mathrm{T}$ ( $\mathrm{rs} 1143634)]$ $($ IL-1 $\beta+3954 \mathrm{C}>\mathrm{T})$ [interleukin- $1 \beta+3954$ previously described as interleukin- $1 \beta+3953$ (López et al., 2005) ] gene polymorphisms. IL-1 has been frequently associated with inflammatory events in connective and bone tissues (Alhashimi, 2001). Moreover, IL-1 $\beta$ has been characterized as a potent bone-resorptive cytokine and implicated as a key component of the complex pathways leading to root resorption (Hartsfield, 2004).

Over the last decade, a number of case-control studies (Al-Qawasmi et al., 2003a; Bastos Lages et al., 2009; Gülden et al., 2009; Tomoyasu, 2009; Iglesias-Linares, 2012a,b; Linhartova, 2012) have been conducted to investigate the association between the IL- $1 \beta+3954$ $\mathrm{C}>\mathrm{T}$ polymorphism and EARR risk in orthodontic treatment patients. However, the results of these studies are conflicting. The purpose of this meta-analysis was to determine whether genetic variants of the IL1 $\beta+3954$ gene polymorphisms are positively or negatively associated with a predisposition to post-orthodontic treatment EARR.

\section{MATERIAL AND METHODS}

\section{Search strategy and selection criteria}

We conducted a literature search in PubMed, Embase, and other resources (including 
records entered by October 2012) using the following key words: "external apical root resorp-

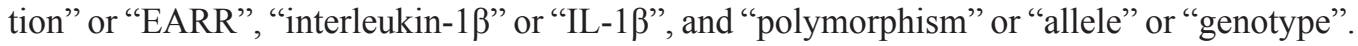
No restriction was made on time-period, sample size, population, language or type of report, but conducted on human subject. All eligible articles were retrieved, and their references were checked for other relevant studies missed during electronic searching.

\section{Inclusion and exclusion criteria}

The following criteria were used to include published studies: 1) case-control studies evaluating associations between IL-1 $\beta+3954 \mathrm{C}>\mathrm{T}$ polymorphisms and EARR risk; 2) sufficient genotype data presented to calculate odds ratios (ORs) and $95 \%$ confidence intervals (95\%CIs); and 3) clear description of EARR and the sources of cases and controls. Major reasons for exclusion of studies were 1) review, or editorial, or comment; 2) insufficient data; and 3) duplication.

\section{Data extraction and study design}

We extracted the following information from the included studies: first author, year of publication, number of cases and controls, and genotype frequency of cases and controls. Two investigators independently reviewed all the articles, and the data were checked by other investigators. To ensure the accuracy of extracted information, 2 investigators blinded to the identity information of the studies judged inclusion and exclusion.

\section{Statistical analysis}

The strength of the association between EARR and the IL- $1 \beta+3954 \mathrm{C}>\mathrm{T}$ polymorphism was estimated using ORs with the corresponding 95\%CIs. The pooled ORs were obtained using a co-dominant model (CC vs TT, CT vs TT), a dominant model (CC + CT vs TT), and a recessive model $(\mathrm{CC}$ vs $\mathrm{CT}+\mathrm{TT})$.

The maxillary central incisors have the highest heritability estimates $\left(\mathrm{h}^{2}=79 \%\right)$ of all teeth examined (Harris et al., 1997) and are at the greatest risk for EARR (Newman, 1975; Al-Qawasmi et al., 2003a). Tomoyasu et al. (2009) provided the apical root resorption of maxillary incisor, mandibular incisor, mandibular mesial molar, and mandibular distal molar values for this study. We calculated only the OR of maxillary incisor apical root resorption for the meta-analysis.

Both Cochran's Q statistic (Cochran, 1954) to test for heterogeneity and the $I^{2}$ statistic to quantify the proportion of total variation due to heterogeneity (Higgins et al., 2003) were calculated. A P value of more than 0.10 for the Q statistic or an $I^{2}$ less than $50 \%$ indicated a lack of heterogeneity across studies, allowing for the use of a fixed-effects model [MantelHaenszel method (Mantel and Haenszel, 1959)]; otherwise, we used the random-effects model [DerSimonian and Laird method (DerSimonian and Laird, 1986)].

To investigate more thoroughly the possible sources of between-study heterogeneity, we applied subgroup and sensitivity analyses when heterogeneity was observed. Publication bias was investigated with a funnel plot; an asymmetric plot suggested possible bias. In addition, funnel plot asymmetry was assessed using the method of Begg's (Begg and Mazumdar, 
1994) and Egger's test (Egger et al., 1997). P values of $<0.05$ and $>0.05$ indicated publication bias or no bias, respectively.

Statistical analyses were performed with SPSS version 13.0 (SPSS Inc., Chicago, IL, USA) and STATA (version 9.0). All P values were 2-sided. To ensure the reliability and accuracy of the results, 2 authors uploaded the data.

\section{RESULTS}

\section{Characteristics of included studies}

We identified 17 relevant studies after searching the databases: PubMed $(\mathrm{N}=8)$, Embase $(\mathrm{N}=7)$, and other sources $(\mathrm{N}=2)$. A total of 15 potentially eligible studies were identified for detailed evaluation (Figure 1). According to the exclusion criteria, 8 publications were excluded, including 5 publications containing overlapping data, 2 publications with inadequate data, and 1 publication that was a review. We included 7 individual case-control studies. Table 1 presents a brief description of these studies, which were published between 2003 and 2012. Four studies were conducted in Europe, 1 study in North America, 1 study in South America, and 1 study in Asia. Sample size of the studies varied from 51 (Bastos Lages et al., 2009) to 118 (Al-Qawasmi et al., 2003a).

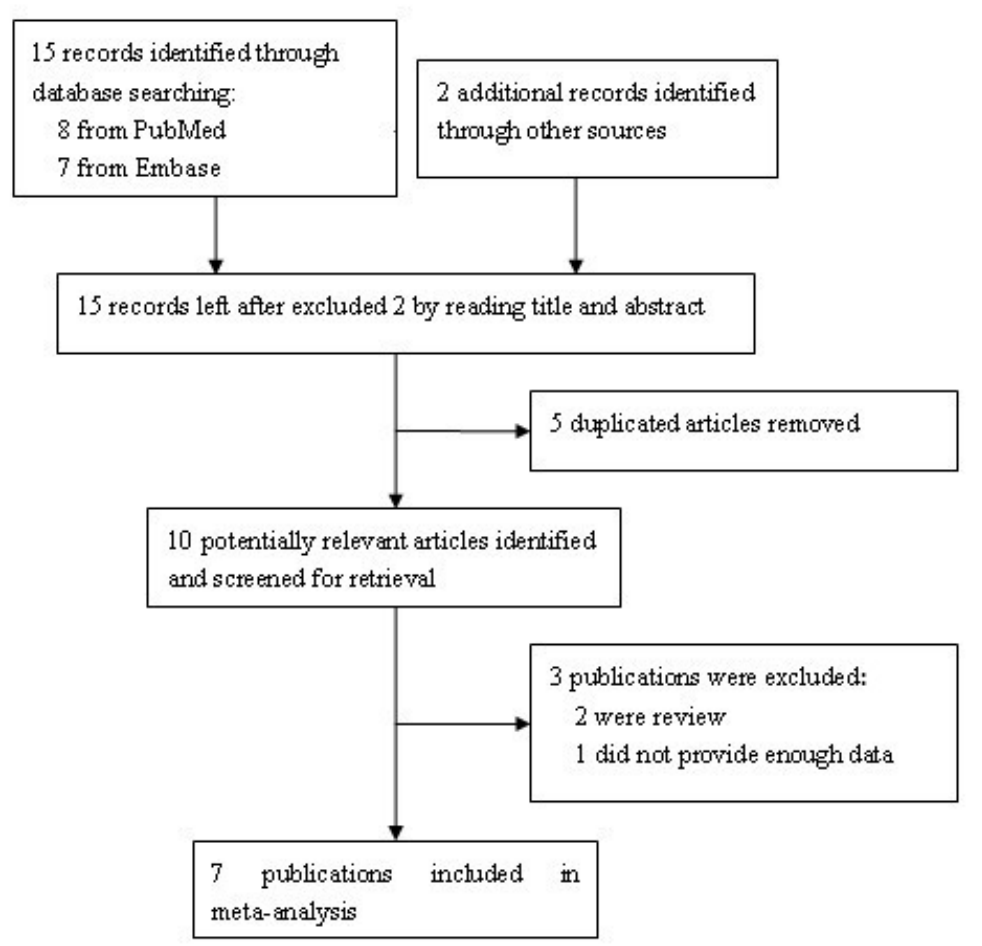

Figure 1. Flow chart of selection of studies and specific reasons for exclusion from the meta-analysis. 
Table 1. Characteristics of the studies included.

\begin{tabular}{|c|c|c|c|c|c|c|c|c|}
\hline \multirow[t]{2}{*}{ References } & \multirow[t]{2}{*}{ Country } & \multirow{2}{*}{$\begin{array}{c}\text { No. of } \\
\text { case/control }\end{array}$} & \multicolumn{3}{|c|}{ EARR $(\geq 2 \mathrm{~mm})[\mathrm{N}(\%)]$} & \multicolumn{3}{|c|}{ Control $(<2 \mathrm{~mm})[\mathrm{N}(\%)]$} \\
\hline & & & $\mathrm{CC}$ & CT & TT & $\mathrm{CC}$ & $\mathrm{CT}$ & TT \\
\hline Al-Qawasmi et al. (2003a) & USA & 118 & \multicolumn{6}{|c|}{$\mathrm{CC} / \mathrm{CT}+\mathrm{TT}: \mathrm{OR}=5.6(95 \% \mathrm{CI}=1.89-21.20)$} \\
\hline Bastos Lages et al. (2009) & Brazil & $23 / 38$ & $11(18.0)$ & $7(11.5)$ & $5(8.3)$ & $6(9.8)$ & $12(19.6)$ & $20(32.8)$ \\
\hline Gülden et al. (2009) & Germany & $45 / 49$ & $17(37.7)$ & $26(57.7)$ & $2(4.44)$ & $28(57.1)$ & $16(36.4)$ & $5(10.2)$ \\
\hline Tomoyasu et al. (2009) & Japan & $27 / 24$ & $23(85.2)$ & $4(14.8)$ & - & $22(91.7)$ & $2(8.3)$ & - \\
\hline Iglesias-Linares et al. (2012a) & Spain & $39 / 54$ & $28(71.8)$ & $4(10.3)$ & $7(17.9)$ & $27(50.0)$ & $26(48.1)$ & $1(1.9)$ \\
\hline Iglesias-Linares et al. (2012b) & Spain & $25 / 29$ & $17(68)$ & $8(32)$ & - & $11(37.9)$ & $16(55.2)$ & $2(6.9)$ \\
\hline Linhartova et al. (2012) & Czech Republic & $32 / 74$ & $18(56.3)$ & $12(37.5)$ & $2(6.2)$ & $38(51.4)$ & $32(43.2)$ & $4(5.4)$ \\
\hline
\end{tabular}

$\mathrm{C}=$ cytosine $\mathrm{CC}=$ homozygous subjects with cytosine in both alleles; $\mathrm{CT}=$ heterozygous subjects with cytosine in 1 allele and thymine in the other; $\mathrm{T}=$ thymine; $\mathrm{TT}=$ homozygous subjects with thymine in both alleles. $\mathrm{OR}=$ odds ratio; $95 \% \mathrm{CI}=95 \%$ confidence interval.

\section{Meta-analysis results}

Figure 2A-D shows the association of EARR risk with the IL-1 $\beta+3954 \mathrm{C}>\mathrm{T}$ polymorphism. Overall, the variant genotypes (CC and $\mathrm{CT}$ ) of this polymorphism were unassociated with EARR risk compared with the wild-type TT homozygote $(\mathrm{CC} v s \mathrm{TT}$, OR $=1.28$, $\left.95 \% \mathrm{CI}=0.27-6.08, \mathrm{P}_{\text {heterogeneity }}=0.023 ; \mathrm{CT} v s \mathrm{TT}, 0.74,95 \% \mathrm{CI}=0.11-5.02, \mathrm{P}_{\text {heterogeneity }}=0.003\right)$. Similarly, no associations were observed in the dominant and recessive models (dominant model, $\mathrm{CC}+\mathrm{CT}$ vs TT: $\mathrm{OR}=1.08,95 \% \mathrm{CI}=0.24-4.86, \mathrm{P}_{\text {heterogeneity }}=0.017$; recessive model, CC vs CT + TT: OR $\left.=1.85,95 \% \mathrm{CI}=0.87-3.93, \mathrm{P}_{\text {heterogeneity }}=0.002\right)$.

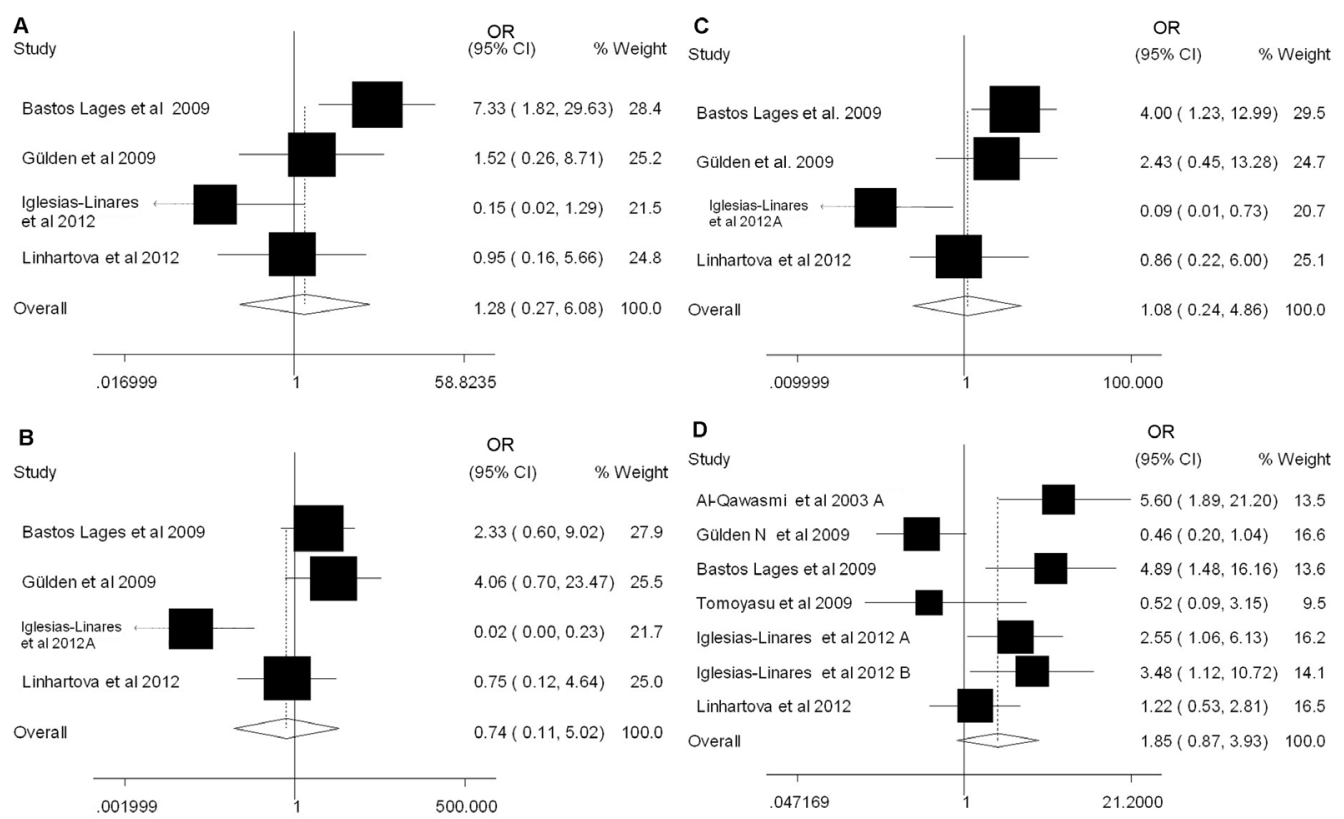

Figure 2. Forest plots of EARR risk associated with the interleukin- $1 \beta$ polymorphism. The squares and horizontal lines correspond to the study-specific OR and $95 \% \mathrm{CI}$. The area of the squares reflects the study-specific weight (inverse of the variance). The diamonds represent the pooled OR and $95 \% \mathrm{CI}$. A. CC vs TT. B. CT vs TT. C. TT + CT vs TT. D. CC vs CT+TT. 


\section{Heterogeneity and sensitivity analyses}

Heterogeneity was found among studies in homozygote or heterozygote comparisons (CC vs TT or CT vs TT) and dominant or recessive models. We did not conduct a subgroup analysis because the co-dominant and dominant models had only 3 studies. We conducted a sensitivity analysis of the influence of each study on the pooled OR by repeating the metaanalysis omitting 1 study each time. No matter which study was omitted, the heterogeneity remained.

\section{Publication bias}

The funnel plot and Begg's and Egger's tests were performed to evaluate publication bias in the EARR literature. Figure 3 displays a funnel plot that examined the IL- $1 \beta+3954$ $\mathrm{C}>\mathrm{T}$ polymorphism and overall EARR risk included in the meta-analysis in the recessive model comparison. The plot shapes revealed no evidence of asymmetry. The statistical results still showed no publication bias (CC vs TT: Begg's test $\mathrm{P}=0.089$, Egger's test $\mathrm{P}=0.003$; CT vs TT: Begg's test $\mathrm{P}=0.308$, Egger's test $\mathrm{P}=0.190$; dominant model: Begg's test $\mathrm{P}=0.308$, Egger's test $P=0.108$; recessive model: Begg's test $P=0.133$, Egger's test $P=0.495$ ).

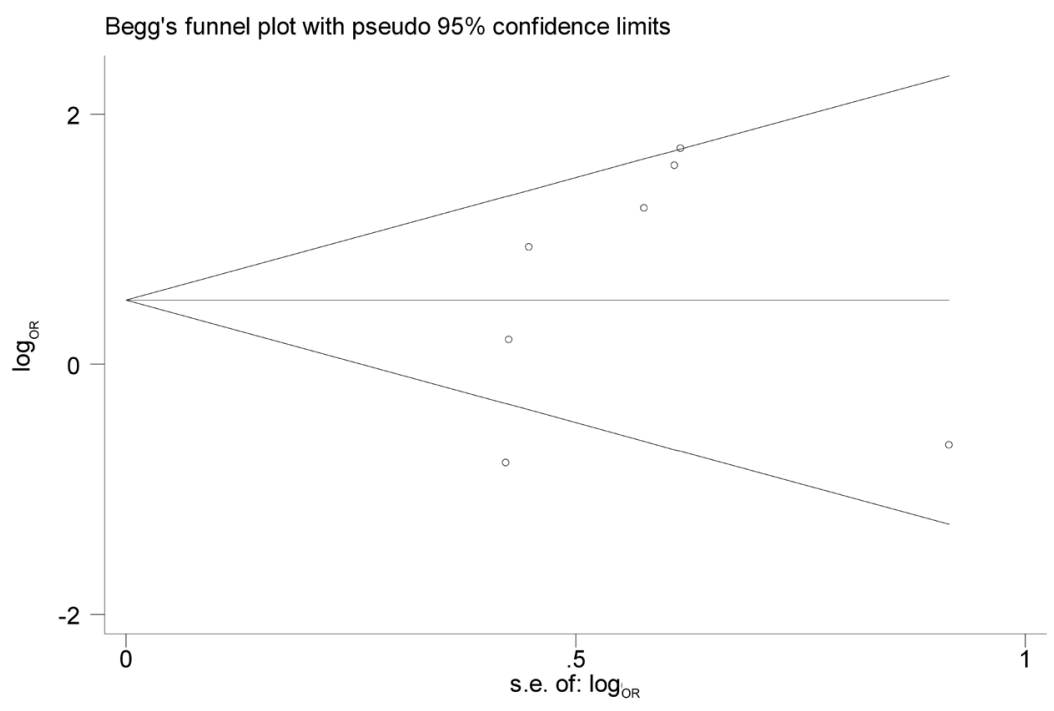

Figure 3. Funnel plot for publication bias test $(\mathrm{CC} v s \mathrm{CT}+\mathrm{TT})$. Each point represents a separate study for the indicated association.

\section{DISCUSSION}

The meta-analysis included 577 participants from 7 case-control studies and explored the association between the IL- $1 \beta+3954 \mathrm{C}>\mathrm{T}$ polymorphism and EARR risk. To our knowledge, this meta-analysis was the first comprehensive assessment of the relationship between 
IL-1 $\beta+3954 \mathrm{C}>\mathrm{T}$ and EARR risk. Overall, we found no significant association between the IL-1 $\beta+3954 \mathrm{C}>\mathrm{T}$ polymorphism and EARR susceptibility among orthodontic treatment patients. We identified several reasons for this lack of association. First, the included studies had small sample sizes, with all but 1 study by Al-Qawasmi et al. (2003a) including more than 100 participants. Second, the frequency distribution of the gene polymorphisms was significantly different among different ethnic groups. For example, the frequency of the TT genotype ranged from null in the Asian group to $32.8 \%$ in the South American group. The variation in genotype frequency among ethnic groups may contribute to the lack of a significant association overall. Third, some confounding factors - such as length of treatment, sex, and use of extractions - that may affect have affected the incidence of EARR were not recognized or taken into account, which may have led to inaccurate results.

Our analysis showed that the IL- $1 \beta+3954 \mathrm{C}>\mathrm{T}$ polymorphism remains an inadequate marker for EARR susceptibility. Multiple pathways may be involved in root resorption and function as a complex (James Jr., 2008). Viecilli et al. (2009) have found that upstream P2X purinoceptor 7 reinforces IL-1 $\beta$ and EARR risk. In addition to the effect of IL-1 $\beta$ on bone turnover and the local effect of tooth root strain increasing root resorption (Al-Qawasmi, 2004), P2RX7 may also mediate the resolution of inflammation through IL- $\beta$ via macrophage recruitment so that inflammation does not become chronic.

Though no association between the IL- $1 \beta+3954 \mathrm{C}>\mathrm{T}$ polymorphism and the risk of EARR was found, evidence from animal studies (Al-Qawasmi et al., 2004; Shornick et al., 1996) have shown that the IL-1 $\beta+3954 \mathrm{C}>\mathrm{T}$ polymorphism is positively related to EARR. In a study by Al-Qawasmi et al. (2004) 33 male mice of the wild-type strain (C57BL/6J,+/+) and the IL- $1 \beta$ knockout were divided into control or treatment groups. The number of control $(\mathrm{C})$ or treated $(\mathrm{T})$ mice per group were as follows: wild-type $(\mathrm{C}=7, \mathrm{~T}=8)$ and knockout $(\mathrm{C}$ $=8, \mathrm{~T}=10)$. Both groups were fed a diet of finely milled mouse chow ad libitum to minimize discomfort and appliance distortion. No differences in MRR were found between the untreated wild-type and knockout mice. Results showed a significant difference in both the wild-type and knockout animals with treatment compared with controls. A significant difference occurred between treated wild-type and treated knockout mice, with the knockout mice having approximately 3 times the percent MRR of that in the treated wild-type mice.

In a human study, Pociot et al. (1992) found that allele $\mathrm{C}$ at the IL-1 $\beta$ gene, known to decrease IL-1 cytokine production in vivo (di Giovine et al., 1995), resulted in low IL-1 production that caused relatively less catabolic bone modeling in the cortical bone interface of the periodontal ligament (PDL) owing to a decreased number of osteoclasts associated with lower levels of this cytokine. Inhibition of bone resorption in the direction of tooth movement maintains prolonged dynamic loading on tooth roots adjacent to the compressed PDL, causing more root resorption owing to fatigue failure of the root. In cases of high IL-1 production associated with allele 2, compressed PDL space is restored by resorption of the bone interface of the PDL, resulting in only mild root resorption that is controlled by cementum healing.

Al-Qawasmi et al. (2003a) have reported that subjects with the CC genotype at IL-1 $\beta$ have, on average, $1.3 \mathrm{~mm}$ greater EARR than that of subjects with either the CT or TT genotypes. This difference between the genotype groups was highly significant $(\mathrm{P}<0.001)$ and accounted for approximately $15 \%$ of the total variation in EARR. The transmission of the CC haplotype from parent to child was associated, on average, with $1 \mathrm{~mm}$ more EARR than that associated with the transmission of the TT haplotype. By contrast, the transmission of haplo- 
types that include allele 2 of the IL-1 $\beta$ ge1ne decreases susceptibility to EARR with a 2 -fold increase in resistance if the haplotype includes allele 2 for the IL-1 $\alpha$ marker (Al-Qawasmi et al., 2003a).

\section{Advantages and limitations}

Our meta-analysis had some advantages. First, no publication bias was detected, indicating that the whole pooled result may be publication unbiased. Second, this meta-analysis is the first description of a genetic marker that identifies people susceptible to EARR before beginning orthodontic treatment. Third, substantial numbers of cases and controls were pooled from various studies, which significantly increased the statistical power of the analysis.

This meta-analysis also had some limitations. First, different studies used different EARR measurements, such as panoramic radiographs and lateral cephalograms. Different radiographs have different precision for measuring EARR and may decrease the precision of the outcome of analyses. Another limitation of this analysis is the lack of original data, which resulted in the exclusion of factors such as age and inflammation, which may modify the risk estimates, as reported in previous publications. Thus, further studies with better confounding factor adjustments are needed. Third, meta-analysis is a type of retrospective study, and recall and selection bias might exist.

The IL-1 $\beta+3954 \mathrm{C}>\mathrm{T}$ polymorphism is unassociated with susceptibility to EARR. Nevertheless, IL-1 $\beta+3954$ may be a promising gene for predicting EARR in orthodontic patients, and multicenter and better-controlled studies are required.

\section{REFERENCES}

Al-Qawasmi RA, Hartsfield JK Jr, Everett ET, Flury L, et al. (2003a). Genetic predisposition to external apical root resorption. Am. J. Orthod. Dentofacial Orthop. 123: 242-252.

Al-Qawasmi RA, Hartsfield JK Jr, Everett ET, Flury L, et al. (2003b). Genetic predisposition to external apical root resorption in orthodontic patients: linkage of chromosome-18 marker. J. Dent. Res. 82: 356-360.

Al-Qawasmi RA, Hartsfield JK, Hartsfield JK Jr, Everett ET, et al. (2004). Root resorption associated with orthodontic force in IL-1Beta knockout mouse. J. Musculoskelet. Neuronal Interact. 4: 383-385.

Al-Qawasmi RA, Hartsfield JK Jr, Everett ET, Weaver MR, et al. (2006). Root resorption associated with orthodontic force in inbred mice: genetic contributions. Eur. J. Orthod. 28: 13-19.

Alhashimi N, Frithiof L, Brudvik P and Bakhiet M (2001). Orthodontic tooth movement and de novo synthesis of proinflammatory cytokines. Am. J. Orthod. Dentofacial Orthop. 119: 307-312.

Bastos Lages EM, Drummond AF, Pretti H, Costa FO, et al. (2009). Association of functional gene polymorphism IL1 beta in patients with external apical root resorption. Am. J. Orthod. Dentofacial Orthop. 136: 542-546.

Begg CB and Mazumdar M (1994). Operating characteristics of a rank correlation test for publication bias. Biometrics 50: 1088-1101.

Cochran WG (1954). The combination of estimates from different experiments. Biometrics 10: 101-29.

DerSimonian R and Laird N (1986). Meta-analysis in clinical trials. Control Clin. Trials 7: 177-188.

di Giovine FS, Cork MJ, Crane A and Mee JB (1995). Novel genetic association of an IL-1B gene variation a+3953 with IL-1B protein production and psoriasis. Cytokine 7: 606.

Egger M, Davey SG, Schneider M and Minder C (1997). Bias in meta-analysis detected by a simple, graphical test. BMJ 315: 629-634.

Gülden N, Eggermann T, Zerres K and Beer M (2009). Interleukin-1 polymorphisms in relation to external apical root resorption (EARR). J. Orofac Orthop. 70: 20-38.

Harris EF, Kineret SE and Tolley EA (1997). A heritable component for external apical root resorption in patients treated orthodontically. Am. J. Orthod. Dentofacial Orthop. 111: 301-309.

Hartsfield JK Jr, Everett ET and Al-Qawasmi RA (2004). Genetic factors in external apical root resorption and orthodontic 
treatment. Crit. Rev. Oral Biol. Med. 15: 115-122.

Higgins JP, Thompson SG, Deeks JJ and Altman DG (2003). Measuring inconsistency in meta-analyses. BMJ 327: $557-$ 560.

Iglesias-Linares A, Yanez-Vico R, Ballesta-Mudarra S, Ortiz-Ariza E, et al. (2012a). Postorthodontic external root resorption is associated with IL1 receptor antagonist gene variations. Oral Dis. 18: 198-205.

Iglesias-Linares A, Yanez-Vico RM, Ortiz-Ariza E, Ballesta S, et al. (2012b). Postorthodontic external root resorption in root-filled teeth is influenced by interleukin-1beta polymorphism. J. Endod. 38: 283-287.

James KH Jr (2008). Personalized orthodontics, the future of genetics in practice. Semin. Orthod. 14: 166-171.

Linhartova P, Cernochova P and Izakovicova HL (2012). IL1 gene polymorphisms in relation to external apical root resorption concurrent with orthodontia. Oral Dis. doi: 10.1111/j.1601-0825.2012.01973.x.

López NJ, Jara L and Valenzuela CY (2005). Association of interleukin-1 polymorphisms with periodontal disease. $J$. Periodontol. 76: 234-243.

Mantel N and Haenszel W (1959). Statistical aspects of the analysis of data from retrospective studies of disease. $J$. Natl. Cancer Inst. 22: 719-748.

Newman WG (1975). Possible etiologic factors in external root resorption. Am. J. Orthod. 67: 522-539.

Pociot F, Molvig J, Wogensen L, Worsaae H, et al. (1992). A TaqI polymorphism in the human interleukin-1 beta (IL-1 beta) gene correlates with IL-1 beta secretion in vitro. Eur. J. Clin. Invest. 22: 396-402.

Shornick LP, De Toqni P, Mariathasan S, Goellner J, et al. (1996). Mice deficient in IL-1beta manifest impaired contact hypersensitivity to trinitrochlorobenzone. J. Exp. Med. 183: 1427-1436.

Tomoyasu Y, Yamaguchi T, Tajima A and Inoue I (2009). External apical root resorption and the interleukin-1B gene polymorphism in the Japanese population. Orthod. Waves 68: 152-157.

Viecilli RF, Katona TR, Chen J, Hartsfield JK Jr, et al. (2009). Orthodontic mechanotransduction and the role of the P2X7 receptor. Am. J. Orthod. Dentofacial Orthop. 135: 694-16.

Wehrbein H, Fuhrmann RA and Diedrich PR (1995). Human histologic tissue response after long-term orthodontic tooth movement. Am. J. Orthod. Dentofacial Orthop. 107: 360-371. 